\title{
Dasboard Monitoring Mahasiswa Dan Lulusan Untuk Meningkatkan Potensi Penerimaan Mahasiswa Baru Serta Strategi Pemasaran
}

\author{
Leo Putrawan Handho' ${ }^{1}$, Susan Dian Purnamasari² \\ 1,2Information System Departement, Bina Darma University, Palembang, Indonesia \\ Email: leohandho.281198@gmail.com ${ }^{1}$, susandian@binadarma.ac.id ${ }^{2}$
}

\begin{abstract}
In the development of information technology today, information technology can be used in various aspects of the world of work to help and facilitate the work, one of which is in the field of education or academic. One example is at a university. The university is very important in looking at and monitoring the performance of its students and graduates, to support the need for information quickly and up to date on various business processes, so that executives at a university can see the development and analyze the data well. This research will use the science of information technology namely business intelligence by using the OLAP (Online Analyctical Processing) method that there are stages in it, among others, Analysis Services Project, Integration Service Project, and Reportin. This research was designed with a monitoring system through a dashboard. This dashboard with a Business Intelligence perspective not only dynamically monitors, but also provides predictive results information to support decisions for executives at a university.
\end{abstract}

Keywords: Business Intelligence, Dashboard, Monitoring students graduate

\section{PENDAHULUAN}

Dalam bidang pendidikan atau akademik yaitu universitas, memiliki banyak fakultas dan program studi di dalamnya. Dalam hal tersebut, baik pada level fakutas maupun program studi perlu melakukan suatu proses monitoring secara terus-menerus terhadap perkembangan sebuah informasi dari performa mahasiswa dan lulusannya. Proses monitoring tersebut sangat memerlukan sebuah data - data dari mahasiswa dan lulusan tersebut. Dari data tersebut itulah nantinya 
akan di olah dan di jadikan sebuah laporan untuk pihak eksekutif dalam bentuk dashboard untuk menyajikan informasi yang ringkas dan mudah di pahami.

Sebuah informasi merupakan fasilitas yang sangat penting dalam menunjang sebuah kegiatan dalam pengambilan sebuah keputusan, dengan adanya sebuah informasi yang berkualitas dan akurat ini dan di tunjang dengan memanfaatkan sebuah teknologi informasi menggunakan teknik business intelligence. Kemampuan yang dimiliki teknologi business intelligence antara lain untuk melakukan pengelolahan data menjadi sebuah pengetahuan yang kemudian di kumpulkan menjadi sebuah informasi yang dapat membantu pimpinan dalam melakukan tindakan dan pengambilan keputusan yang tepat [1]. Data-data yang ada antara lain dimulai dari alur mahasiswa yang mendaftar, dan proses perkuliahan mahasiswa sampai mahasiswa tersebut lulus dan di wisuda, tentunya terdapat data-data penting, seperti data profil mahasiswa, nilai-nilai mahasiswa per-mata kuliah, IP setiap semester, data profil dari lulusan dan IPK akhir yang di dapat oleh para lulusan.

Proses monitoring mahasiswa dan lulusan ini memerlukan data dan informasi yang di ambil dari banyak bagian dengan berbagai format data. Pada kenyataan tersebut, dokumentasi dalam penyimpanan data masih belum terintegrasi dan terjadi banyaknya format dalam penyimpanan data. Businnes Intelligence adalah serangkaian aplikasi teknologi untuk menyelesaikan permasalahan tersebut, yaitu dengan mengumpulkan, mengintegrasikan dan menyimpan data serta melakukan analisis data tersebut untuk membantu pihak eksekutif unversitas dalam pengambilan keputusannya [2]. Dalam menentukan sebuah keputusan pihak eksekutif universitas melihat berdasarkan informasi yang telah diolah menggunakan teknik bussines intelligence yang di implementasikan menjadi sebuah dashboard monitoring, sehingga informasi dapat di teliti dan di analisa dengan cepat dan mudah dipahami

\section{METODOLOGI PENELITIAN}

\subsection{Metode Pengumpulan Data}

Dalam penelitian ini dilakukan 3 (tiga) tahap aktifitas utama, yaitu :

1) Pengamatan (Observation), Melakukan tinjauan secara langsung ke objek penelitian. Mempelajari permasalahan yang ada di lapangan. Berkaitan dengan judul penelitian yaitu dashboard monitoring untuk pengolahan data mahasiswa dan lulusan. 
https://journal-computing.org/index.php/journal-cisa/index

2) Wawancara (Interview), Memperoleh data-data yang akurat untuk diperlukan pada penelitian melalui wawacara secara langsung kepada sumber-sumber yang tepat dan terpercaya sesuai dengan bidang yang akan di terapkan pada penelitian ini .

3) Studi Pustaka (literature review), Mencari bahan-bahan dan referensi yang mendukung dalam pedefinisian masalah, dengan memahami dan membaca dan mempelajari buku-buku ataupun dengan mengunjungi situs-situs internet terpercaya yang berhubungan dan sejenis dengan penelitian ini.

\subsection{Metode Analisis}

Metode Analisis yang di gunakan pada penelitian ini adalah metode OLAP. Metode OLAP (Online Analytical Processing) memungkinkan untuk di gunakan sebagai penunjang keputusan tentang tindakan apa yang akan di lakukan selanjutnya. Di dalam model data OLAP, informasi di gambarkan secara konseptual seperti cube yang terdiri atas dimensionsdimensions dan measures, Indrajani (2013) [3]. Sedangkan pengertian lainnya metode OLAP adalah metode untuk melakukan analisis terhadap data pada media penyimpanan data (database), yang kemudian dibuat menjadi sebuah laporan yaitu sebuah informasi sesuai dengan permintaan user atau kebutuhan, Hermawan (2005). Berikut adalah tahapan-tahapan OLAP pada pengembangan sistem business intelligence yaitu, Hermawan (2005) [4] :

1) Analisis Kondisi Eksisting (Kondisi Data Sekarang), Bertujuan untuk melihat sumber acuan format data pada objek yang akan diteliti dan di ambil datanya, dianalisa dan dipelajari, apa-apa saja yang akan di ambil dan diolah datanya.

2) Analisis Kebutuhan Data dan Subjek Data Warehouse, Kebutuhan data serta informasi dari sistem yang akan di kembangkan berasal dari sumber data pada tahap analsisis kondisi eksisting sebelumnya, kemudian di susun dan diurutkan berdasar tahapan kebutuhan subjek data warehouse.

3) Proses ETL (extract, transform, load), Proses integrasi data dari berbagai sumber-sumber data, untuk membuat sebuah dimensidimensi dan sebuah table fact untuk menghasilkan sudut pandang tunggal terhadap semua sumber data yang di integrasikan.

4) Schema (Star atau Knowflake), Perancangan schema ini di lakukan dengan menggunakan pemodelan multi-dimensional yang terdiri atas sebuah fact table, yang berelasi dengan beberapa dimensions table yang akan membentuk sebuah data mart. 


\section{HASIL DAN PEMBAHASAN}

\subsection{Proses Extract, Transform, Load (ETL)}

Menurut Varcellis (2009), ETL mengacu pada alat perangkat lunak yang di dedikasikan untuk melakukan proses extract, transform, load data ke dalam data warehouse [5]. Sedangkan Menurut Moss and Atre (2003), ETL adalah proses yang kompleks dalam proyek BI karena kualitas sebuah data warehouse di perhitungkan [6].

\section{1) Proses ETL Dimensi Mahasiswa}

Tahapan-tahapannya antara lain, Step table input mahasiswa di masukkan untuk menginputkan data yang berasal dari data source, kemudian dihubungkan ke step add sequence untuk membuat surogate key. Kemudian Selanjutnya melakukan mapping pada select values untuk memilih field atau data yang dari sumber database mahasiswa ke dimensi mahasiswa.

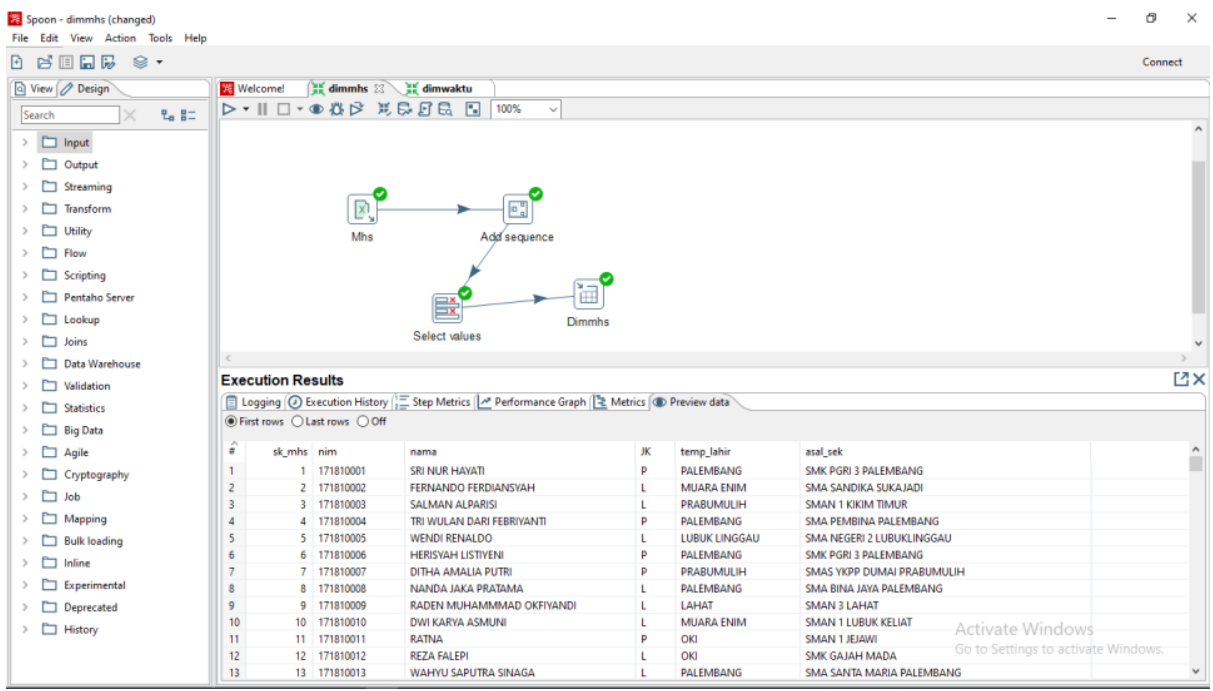

Gambar 1. proses ETL Pada Dimensi Mahasiswa

2) Proses Etl Dimensi Waktu

Dimensi waktu adalah sebuah dimensi yang data-datanya di buat atau di generate sendiri. Setelah proses step add sequence, calculator dimasukkan berfungsi untuk memasukkan kalkulasi atau perhitungan, 
https://journal-computing.org/index.php/journal-cisa/index

Selanjutnya step java script digunakan untuk membuat surogate key pada dimensi waktu. Selanjutnya melakukan mapping pada select values untuk memilih field atau data yang diperlukan pada dimensi waktu, antara lain, bulan, kuartal, dan tahun.

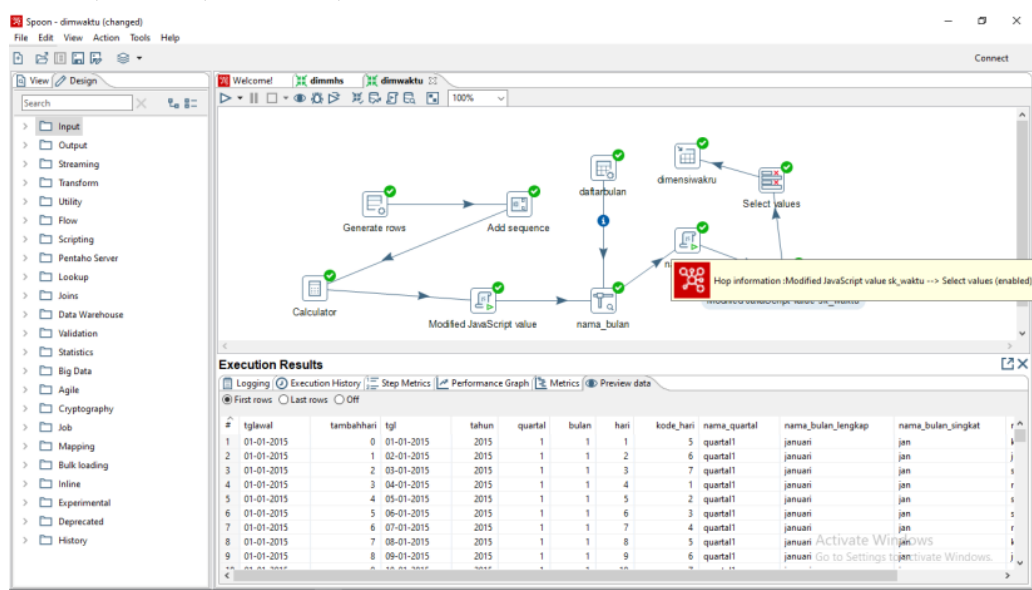

Gambar 2. Proses ETL Dimensi Waktu

3) Proses ETL Tabel Dimensi Status

Pada dimensi Status step-step yang di gunakan antara lain, Microsoft Excel input status di drag untuk memasukkan data yang berasal dari data source, kemudian dihubungkan ke add sequence untuk membuat sebuah surogate key. Kemudian Selanjutnya melakukan mapping pada select values untuk memilih field atau data yang dari sumber database ke dimensi status.

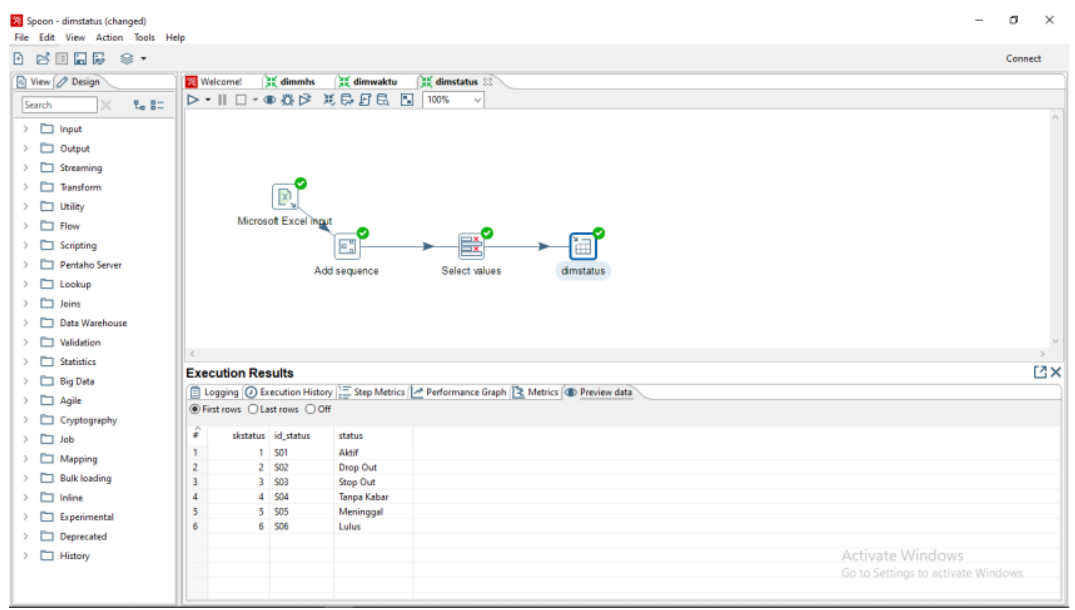

Gambar 3. Hasil proses ETL pada Dimensi Status 


\section{4) Proses Etl Tabel Dimensi Wilayah}

Dimensi Wilayah menggunakan beberapa step pada proses ETL nya yaitu, step microsoft excel input wilayah untuk memasukkan data dari data source, kemudian dihubungkan pada add sequence untuk membuat surogate key. Kemudian Selanjutnya melakukan mapping pada select values untuk memilih field atau data yang dari sumber database dimensi wilayah.

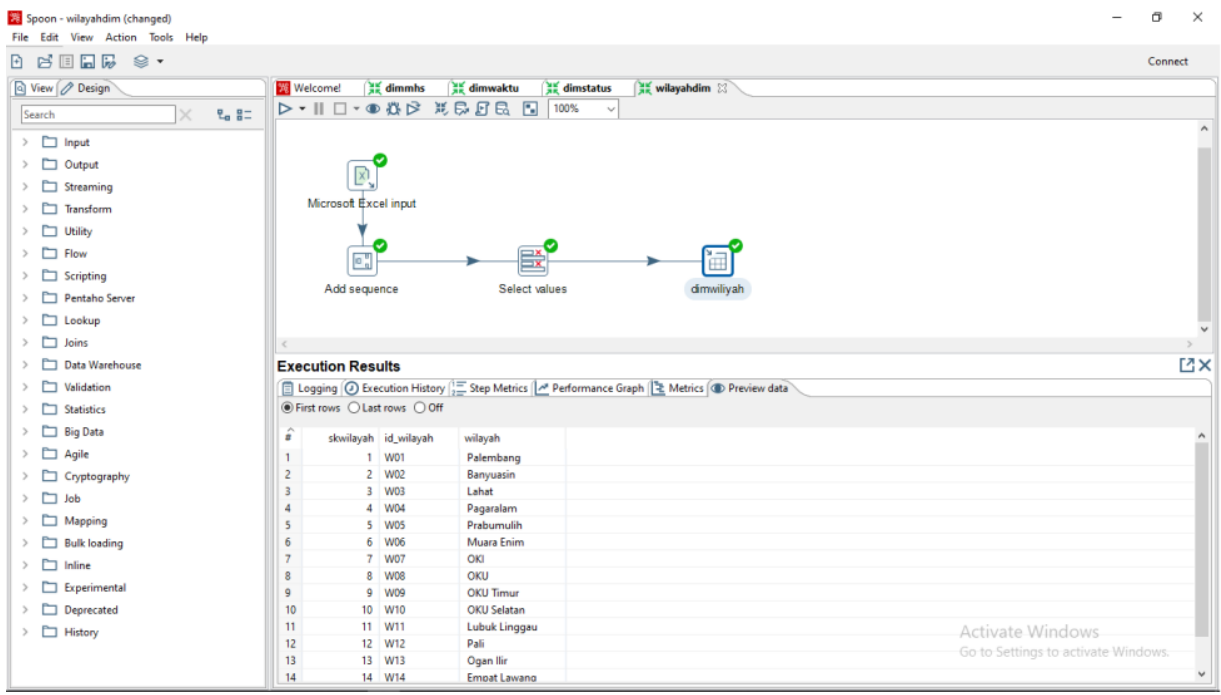

Gambar 4. Hasil proses ETL pada Dimensi Wilayah

\section{5) Dashboard Monitoring Mahasiswa Dan Lulusan}

Pada dashboard Monitoring Mahasiswa dan Lulusan ini menghasilkan grafik monitoring mahasiswa dan lulusan berdasarkan setiap tahunnya, kemudian berdasarkan jenis kelamin, wilayah, dan juga status. Dari grafik tersebut dapat memberikan informasi dan laporan mengenai performa mahasiswa dan lulusan serta memberikan hasil informasi mengenai data mahasiswa dan lulusan berdasarkan waktu dalam kurung waktu yang telah dibuat. 
Vol. 1, No. 2, May 2020 e-ISSN: 2775-2496

https://journal-computing.org/index.php/journal-cisa/index

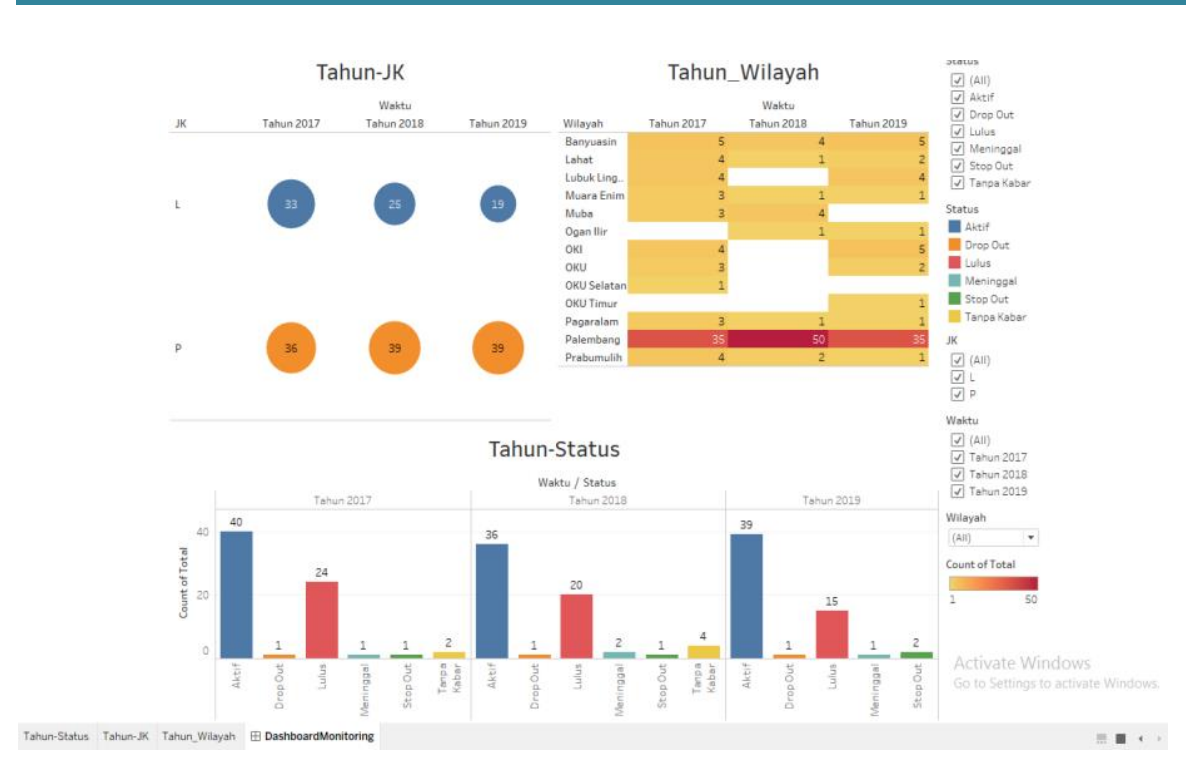

Gambar 5. Dashboard Monitoring Mahasiswa dan Lulusan

\section{KESIMPULAN}

Kesimpulan dari penelitian mengenai dashboard business inteligence untuk monitoring mahasiswa dan lulusan untuk meningkatkan potensi mahasiswa baru dan strategi pemasaran adalah sebagai berikut:

1) Penelitian ini menghasilkan dashboard business inteligence untuk mendukung pengambilan keputusan dan juga monitoring mahasiswa dan lulusan.

2) Permasalahan pada penyajian laporan data mahasiswa dan lulusan, dikarenakan penyajian dan analisis data yang kurang optimal dapat diatasi dengan menggunakan intelligence dashboard monitoring bagi mahasiswa dan lulusan sehingga penyajian, pelaporan dan analisis data dapat berlangsung secara lebih cepat dan optimal.

3) Dengan penggunaan intelligence dashboard sistem ini, maka penyajian data dapat di lakukan secara real-time dan cepat dibandingkan dengan penyajian data atau tampilan informasi data sebelumnya.

4) Laporan atau penyajian informasi data dalam bentuk grafik dashboard tersebut berisikan informasi dari mahasiswa dan lulusan yaitu berupa mahasiswa dan lulusan berdasarkan status, berdasarkan waktu, berdasarkan angkatan, dan berdasarkan wilayah. 
https://journal-computing.org/index.php/journal-cisa/index

\section{DAFTAR PUSTAKA}

[1] S. D. Purnamasari, A. Wijaya, and U. B. Darma, "Dashboard Sistem Informasi Eksekutif Penjualan," p. 10

[2] Nugroho, Adhi Stefan. [2008]. Definisi Business Intelligence

[3] Indrajani. [2013] Pengantar dan Sistem Basis Data. Elex Media Komputindo

[4] Hermawan, [2005] Konsep olap dan aplikasinya menggunakan delphi. Yogyakarta: Andi Publisher

[5] Carlo Vercellis.[2009], Business intelligence: data mining and optimization for decision making. Wiley Online Library

[6] Larissa T Moss and Shaku Atre. [2003], Business intelligence roadmap: the complete project lifecycle for decision-support applications. Addison-Wesley Professional 